\title{
TERJADINYA WARNING LIGHT FUELCLOG ENGINE TURBO PROP PW127F PESAWAT ATR 72-500
}

\author{
Herlina $^{1}$, Hideo David Oktavian ${ }^{2}$ \\ Motor Pesawat, Fakultas Teknik, Universitas Nurtanio Bandung \\ herlinadheni@gmail.com ${ }^{1}$ \\ hideodavid95@gmail.com²
}

\begin{abstract}
Aircraft Air Transport Region (ATR) 72-500 PK-WFG property of Wings Air Company used to engine $P W 127 F$, that is one of turbo prop engine type consist of centrifugal compressor and anullar combustion chamber. When going to RUN-UP engine occurred warning light fuel clog on indicator of fuel clog. Based on inspection indicator cockpit, engine fuel system, and engine component there is limit hard time of outlet fuel filter component reach on 1950 flight hours and contaminate a lot of debress on that surface. The effort to handle replaced outlet fuel filter component (PN: 24436361-01) with new item furhermore, perfomed leak check engine running by means of reference Aircraft Maintenance Manual (AMM 71-01-40). To ensure no leaked on engine and be able to operate as well. With the result that engine going to return to service and decent to flight.
\end{abstract}

Keywords : Fuel System, Fuel Clog, Outlet Fuel Filter, Indicator Warning Light

\section{PENDAHULUAN}

\section{Latar Belakang}

Dunia Penerbangan saat ini menciptakan berbagai tipe pesawat terbang dengan peralatan serta kemampuan terbang yang berbeda-beda dari segi komponen maupun system yang dibuat secanggih mungkin. Hal ini dilakukan demi tercapainya safe operation atau kerja yang aman. Air Transport Regional (ATR)72-500 salah satunya, pesawat ini dipergunakan untuk penerbangan rute jarak dekat dengan menggunakan Engine tipe Turbo Prop PW127F, engine tersebut di produksi oleh Pratt \& Whitney Canada. Jenis turboprop PW127F memiliki system yang tidak jauh berbeda dengan engine pada umumnya, terdiri dari proses pengisapan, kompresi, pembakaran, dan pembuangan akan tetapi energy yang dihasilkan dari pembakaran diteruskan ke turbin shaft untuk memutarkan reduction gearbox beserta propelller. Putaran propeller menghasilkan gaya dorong (thrust) sebesar $85 \%$, dan energy dari hasil pembakaran sisanya $15 \%$ menjadi exhaust jet thrust (hot gas). Pada saat melakukan pengetesan engine RUN-UP di Pesawat ATR 72-500, terjadi permasalahan pada cockpit dengan menyalanya warning lightfuel clog pada indicator fuel clog. Ketika starter generator memutarkan compressor rotor speed dengan symbol $(N)$, High pressure dengan symbol $(H)$, disingkat menjadi $(\mathrm{NH})$, bersamaan menyalakan Ignition, setelah $\mathrm{NH}$ mencapai kecepatan $10 \%$ dibukanya cut off valve mengalir menuju fuel noozle untuk dikabutkan di dalam combustion chamber, ketika NH sudah mencapai $25 \%$ pada indicator cockpit menunjukan munculnya warning lightfuel clog. Kondisi tersebut membuat engine mengalami abnormal condition sehingga engine tidak bekerja secara maksimal.

Berdasarkan keterangan di atas penulis tertarik untuk meneliti permasalahan yang terjadi. Untuk mengetahui permasalahan yang terjadi diperlukan analisa terlebih dahulu, setelah dilakukan analisa 
maka dilanjutkan dengan uji system pada bagianbagian yang berhubungan dengan fuel system.

\section{Rumusan Masalah}

Berdasarkan uraian pada latar belakang di atas, maka rumusan masalah dalam penelitian ini adalah:
1) Apa faktor penyebab warning light fuel clog.
2) Apa akibatnya jika terjadi warning light fuel clog.
3) Upaya-upaya penanggulangan apabila terjadi warning light fuel clog.

\section{TINJAUAN PUSTAKA}

\section{1) General Profil Pesawat ATR}

Pesawat ATR adalah tipe pesawat penumpang regional) jarak pendek bermesin twin-turboprop yang dirancang oleh perusahaan Alenia di negara Perancis-Italia yang berkapasitas 64 sampai 74 penumpang. Penumpang memasuki pesawat melalui pintu belakang (yang sangat jarang digunakan dalam pesawat penumpang) sedangkan pintu depan digunakan untuk memasukkan kargo.

\section{2) General Profil Engine PW127F}

Engine PWI27F adalah jenis turbo propeller dengan two spool gas generator centrifugal compressor dan annular turbine berteknologi tinggi yang dirancang untuk Pesawat ATR 72 500/600 yang dapat menghasilkan tenaga sebesar 2,475SHP max take off rating. Engine ini mempunyai bagian-bagian yang saling berhubungan dan mempunyai fungsi yang berbeda-beda antara lain :
a) Air Inlet Section adalah bagian dari engine yang berfungsi sebagai tempat masuknya udara luar yang dihisap oleh compressor.

b) Compressor ini menggunakan centrifugal compressor dibagi 2 bagian yaitu low pressure dan high pressure. Fungsi dari Compressor pada dasarnya berfungsi untuk menghisap udara luar dari atmosfer dan kemudian meningkatkan / memampatkan pressure-nya untuk kemudian dilanjutkan ke proses pembakaran dan pendinginan.

c) Combustion Chamber menggunakan tipe annular Reverse Flow yang dibuat dengan menggunakan fuel manifold yang melingkar pada bagian luar (Gambar 1) dan menggunakan 2 buah igniter plug untuk pengapian pada ruang combustion chamber dan 14 buah fuel noozle untuk pengabutan bahan bakar. Fungsi combustion chamber pada dasarnya tempat bercampurnya fuel dan udara dibarengi dengan igniter plug sehingga terjadinya pembakaran, kemudian hasil pembakaran tersebut menghasilkan energi panas dan diubah menjadi energi kinetik dengan mengarahkan udara panas tersebut ke siklus turbin.

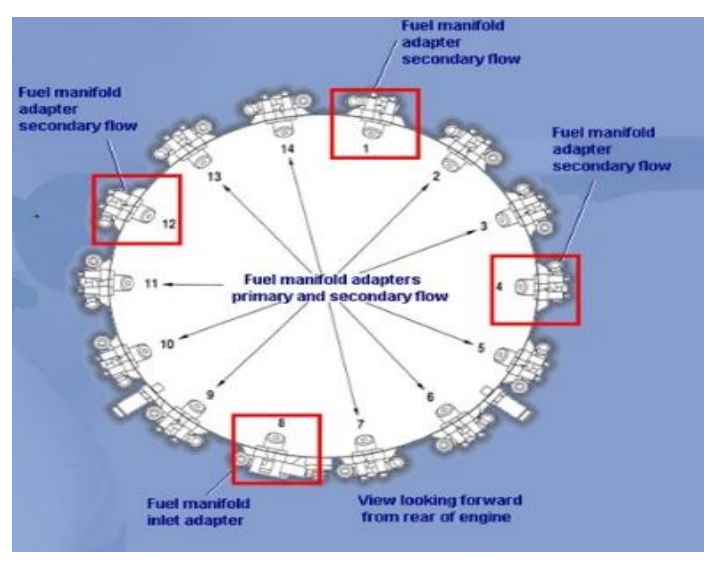

Gambar 1. Combustion Chamber

d) Turbine terdiri dari 2 stages yang tidak saling berhubungan (independent) yaitu turbin kompressor (compressor turbine) yang menggerakkan kompressor dan turbin daya (power turbine) yang akan menggerakkan propeller.

e) Exhaust section merupakan bagian dari engine yang berfungsi untuk mengarahkan gas hasil pembakaran untuk dibuang, tetapi exhaust section ini masih menghasilkan thrust $\pm 20 \%$ yang dibutuhkan oleh pesawat terbang.

3) Engine Control System and Engine Fuel System

a) Engine Control System

\section{Computer Science | Industrial Engineering |Mechanic Engineering |Civil Engineering}


Sebuah engine pada umumnya mempunyai beberapa komponen-komponen yang mampu membantu kinerja engine dan memudahkan untuk memantaunya maka dari itu komponen-komponen tersebut dikelompokkan menjadi beberapa sistem, yang terdiri dari komputer digital untuk mengontrol engine dengan menggunakan sistem Full Authority Digital Engine Control $(F A D E C)$ dengan menggunakan perangkat Electronic Engine Controller (EEC) dapat mengontrol sistematis kerja engine.

b) Engine Fuel System

Berfungsi sebagai pengatur jumlah fuel yang diperlukan pada proses pembakaran di dalam combustion chamber baik di darat maupun di udara, diperlukan suatu sistem. Sistem tersebut harus mampu memberikan porsi fuel pada segala kondisi sesuai dengan yang dibutuhkan.

c) Engine Fuel System Component

Ada beberapa Engine Fuel System Component antara lain:
(1) Pemanas bahan bakar (Fuel Heater)
(2) Temperatur bahan (Fuel Temperatur)
(3) Pompa bahan bakar dan penyaring (Fuel Pump)
(4) Unit Pengontrol bahan bakar (Mechanical Fuel Control Unit)

(5) Pengukur aliran bahan bakar (Fuel Flow Meter)

(6) Pemanas fuel dan pendingin oil (Fuel Heater Oil Cooler)

(7) Pengontrol fuel nozzle (Fuel Divider)

(8) Pengabutan fuel (Fuel Nozzle)

\section{METODE PENELITIAN}

Dalam Penelitian ini menggunakan metode deskriptif analisis yaitu disamping penyajian secara teoritis juga melakukan studi komparasi atau praktek lapangan sebagai data masukan pengungkapan masalah. Sedangkan metode pengumpulan data dilakukan sebagai berikut:

1. Studi Literatur

Suatu metode yang dilakukan dengan mencari data atau dasar teori dari referensi yang berkaitan dengan pokok bahasan.

2. Metode Diskusi

Kegiatan pemahaman dengan cara tanya jawab dengan bertanya kepada engineer yang bersangkutan dalam menangani pemasalahan warning light fuel clog.

3. Teknik Analisis data yang digunakan antara lain:

a. Deskripsi data.

b. Uji sistem pada komponen fuel system dan komponen-komponen yang berkaitan.

c. Menganalisa life time komponenkomponen pada pesawat ATR 72-500 PK-WFG.

\section{HASIL DAN PEMBAHASAN}

Uji sistem dilakukan untuk mengetahui penyebab, akibat dan upaya penanggulangannya terjadinya warning light fuel, dan hasil yang dapat penulis simpulkan antara lain:

\section{Faktor-faktor kemungkinan penyebab menyalanya Warning Light Fuel Clog}

Untuk mengetahui kemungkinan faktor penyebab yang terjadi diperlukan analisa terlebih dahulu, setelah dilakukan analisa maka dilanjutkan dengan pengetesan uji system pada bagian-bagian yang berhubungan dengan fuel system.

1) Kerusakan Indicator Warning Light Apabila indikator rusak maka akan meyebabkan tampilan warning light pada cockpit menjadi on, kemudian dilakukan uji indikator pada indicator warning light, dengan upaya melakukan pemasangan kembali connector fuel bulb temperature yang bertujuan untuk mengetahui apabila terjadi kerusakan pada indicator warning light. Kemudian setelah dilaksanakan uji indikator tersebut, bukan penyebab 
terjadinya warning light fuel clog pada pesawat ATR 72- 500.

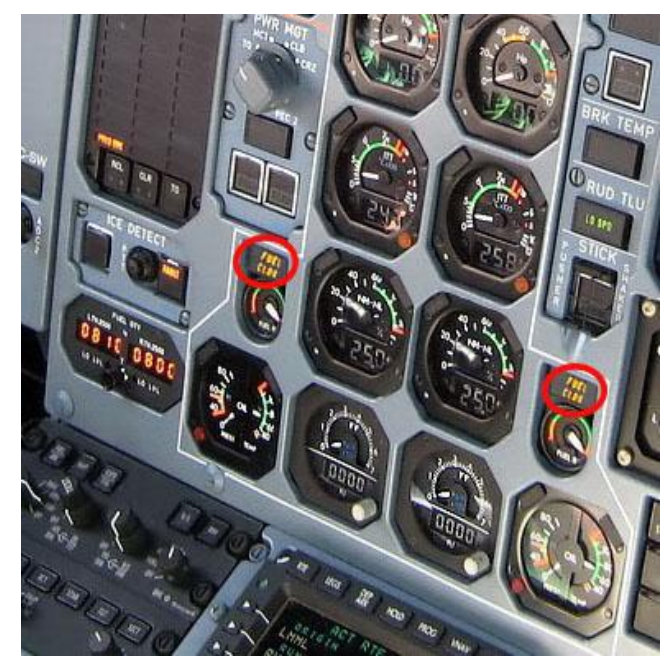

Gambar 2. Indicator Fuel Clog (Cockpit ATR 72500)

2) Outlet Fuel Filter Blok / filter tersumbat Outlet fuel filter dapat tersumbat karena menumpuknya kotoran pada outlet fuel filter, hal ini dapat terjadi karena adanya debris dari gesekan antara gear pump yang terbawa fuel menuju outlet fuel filter secara terus menerus mengakibatkan outlet fuel filter blok. Kemudian dilakukan pengecekan outlet fuel filter dengan cara replacement fuel outlet filter.

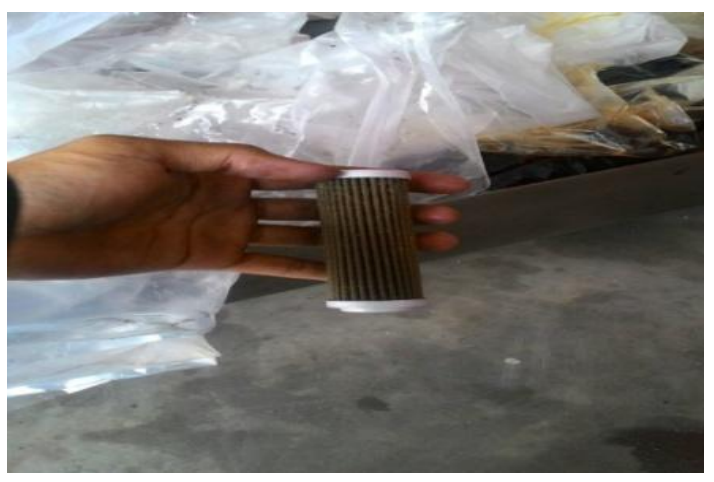

Gambar 3. Outlet Fuel Filter

Setelah dilakukan pengecekan hard time outlet fuel filter berdasarkan engine log book, terdapat limit hard time yang telah mencapai 1950 flight hours. Karena berdasarkan referensi Continous Aircraft Maintenance Program (CAMP) Engine Pratt \& Whitney PW127F 72-05-00 menjelaskan apabila total hard time dari komponen outlet fuel filter mendekati 2000 flight hours harus diganti dengan outlet fuel filter yang baru.

Berdasarkan sejumlah penjabaran yang telah dijelaskan, yang menyebabkan terjadinya warning light fuel clog pada Pesawat ATR 72-500 PK - WFG yaitu adanya penumpukan kontaminasi pada outlet fuel filter dan berdasarkan engine log book, terdapat limit hard time sehingga dari hal tersebut menjadi penyebab terjadinya warning light fuel clog.

\section{Akibat Terjadinya Warning Light Fuel Clog}

Terjadinya warning light fuel clog harus segera ditanggulangi, apabila engine mengalami fuel clog dan dibiarkan secara terus menerus dapat mengakibatkan beberapa faktor yang mempengaruhi kinerja engine antara lain :

1) Engine mengalami abnormal condition Engine mengalami abnormal condition disebabkan beberapa faktor diantaranya; kurangnya pressure fuel yang dikabutkan oleh fuel nozzle dan tidak normalnya aliran fuel sehingga menyebabkan kinerja engine menjadi tidak maksimal.

2) Over heat fuel hp pump

Over heat fuel hp pump disebabkan fuel yang tidak bisa masuk ke dalam outlet fuel filter dikarenakan outlet filter tersumbat sehingga fuel masuk melalui bypass dan membuat aliran fuel menjadi high pressure. Aliran fuel berlanjut masuk kedalam motive flow dan aliran fuel sebagian mengalir melalui impending bypass dan fuel masuk kembali ke fuel hp pump. Sirkulasi aliran fuel tersebut jika dibiarkan secara terus menerus akan membuat fuel $\mathrm{hp}$ pump menjadi over heat. 
3) Dapat mengganggu pengabutan fuel nozzle

Menganggu pengabutan fuel nozzle dikarenakan kurangnya pressure fuel sehingga dapat menyebabkan turunnya tenaga yang dihasilkan pada saat proses pembakaran.

4) Berdasarkan penjabaran dari tinjauan yang telah dijelaskan mengenai beberapa faktor akibat yang dapat mempengaruhi kinerja engine, dan jika tidak segera diantisipasi maka dampaknya akan merusak pada komponen yang berkaitan dengan fuel system

\section{3) Flow Chart Upaya Penanggulangan Terjadinya Warning Light Fuel Clog}

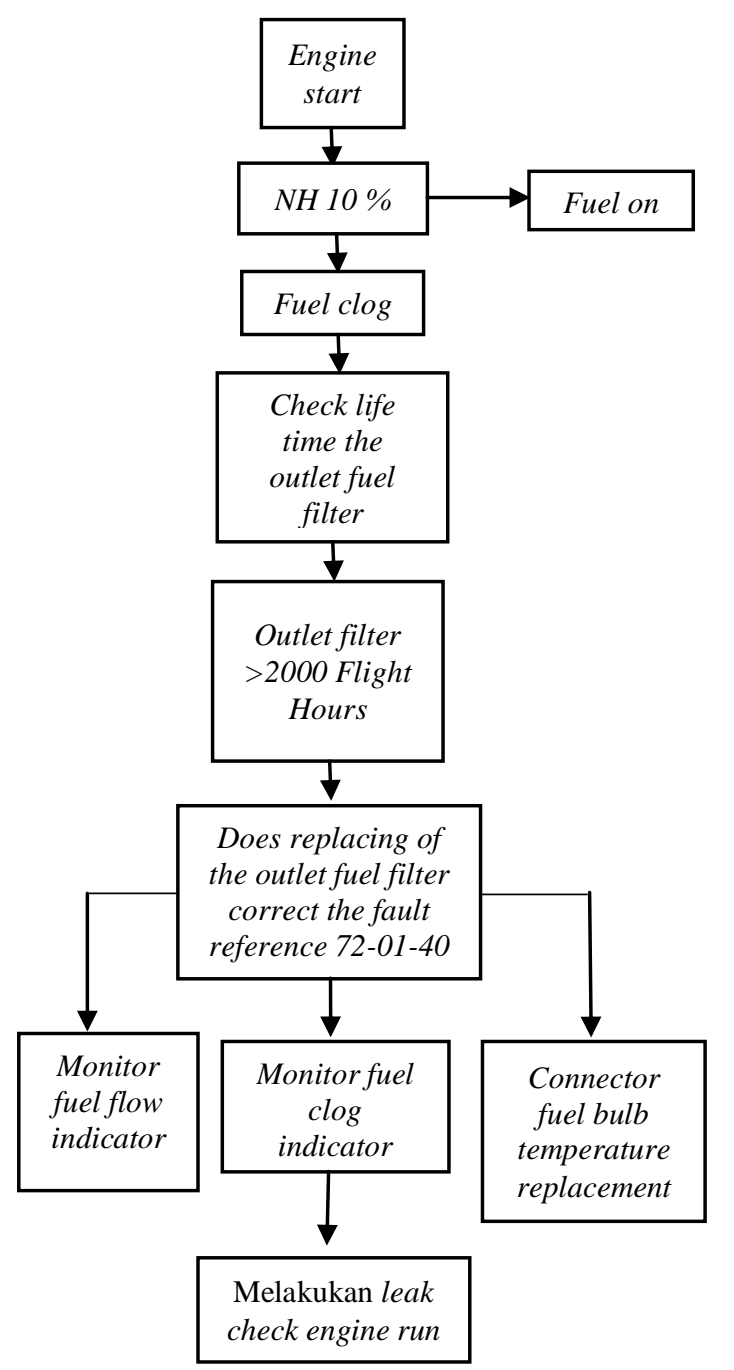

Gambar 4. Engine Failure Diagnosis
Berdasarkan penjabaran dari Gambar 4, merupakan langkah-langkah dalam upaya penanggulangan terjadinya warning light fuel clog. Dari hal tesebut dapat dijelaskan antara lain :

1) Inspection life time of outlet fuel filter

Memeriksa umur komponen outlet fuel filter di engine log book, setelah diperiksa ternyata jumlah lifte time pada komponen outlet fuel filter sudah mendekati 2000 flight hours atau sudah mencapai 1950 flight hours. Komponen tersebut harus diganti karena berpotensi menumpuknya kotoran pada outlet fuel filter yang mengakibatan fuel clog.

2) Outlet fuel filter replacement Outlet fuel filter replacement mempunyai tahapan prosedur berdasarkan panduan EMM 72-01-40 fuel system removal.

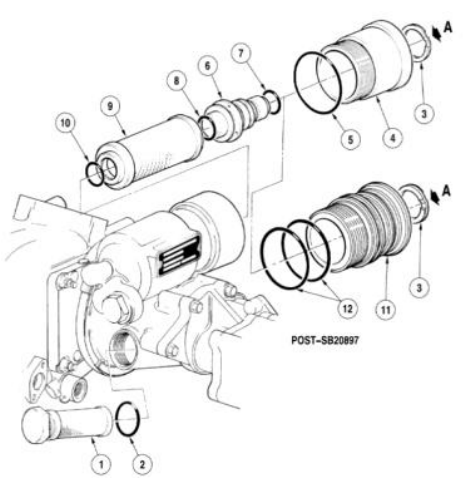

Gambar 5. Outlet Fuel Filter Replacement

3) Fuel flow indicator

Memeriksa aliran fuel yang melewati fuel flow indicator menuju fuel nozzle tidak kurang dari $500 \mathrm{~kg} / \mathrm{h}$ karena hal tersebut berpengaruh terhadap jumlah fuel yang dikabutkan ke combustion chamber yang dapat menyebabkan pembakaran tidak sempurna yang berakibat engine mengalami abnormal condition.

4) Fuel bulb temperature replacement Melepaskan connector fuel bulb temperature dengan menggunakan open wrench $3 / 16$ "

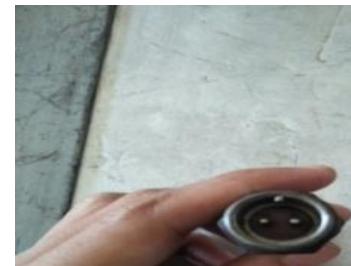


Gambar 7. Kondisi Jarum Green Band Menunjukkan Warna Hijau

Gambar 6. Connector Fuel Bulb Temperature Membersihkan connector fuel bulb temperature dengan menggunakan contact cleaner.

Memasangkan kembali connector fuel bulb temperature ke posisi semula dengan menggunakan tangan dan dikencangkan dengan menggunakan open wrench 3/16". Kemudian memeriksa kembali indicator fuel clog untuk memastikan indikator tidak rusak.

\section{5) Indicator fuel clog}

Memeriksa indicator fuel clog setelah dialirkan bahan bakar ke engine dengan kecepatan $\mathrm{NH}$ sudah mencapai angka 25\% kemudian $\mathrm{NH}$ akan terus naik. Apabila warning light fuel clog sudah tidak muncul lagi maka indikator sudah pada posisi normal. Apabila jarum green bane pada indicator fuel clog yang semula menunjukan pada warna merah sehingga adanya kenaikan temperature pada fuel,sehingga indicator fuel clog pada jarum green bane sudah berubah berada pada posisi warna hijau maka kondisi tersebut sudah berada pada kondisi normal.

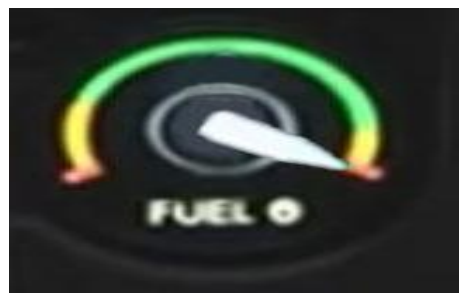

Gambar 6. Kondisi Jarum Green Band Menunjukkan Warna Merah

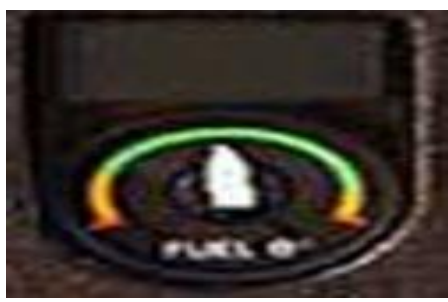

6) Melakukan leak check engine run

a. Memeriksa langsung untuk kebocoran fuel atau oil.

b. Start engine, run engine selama dua menit sampai $80 \%$ torque.

c. Mematikan engine

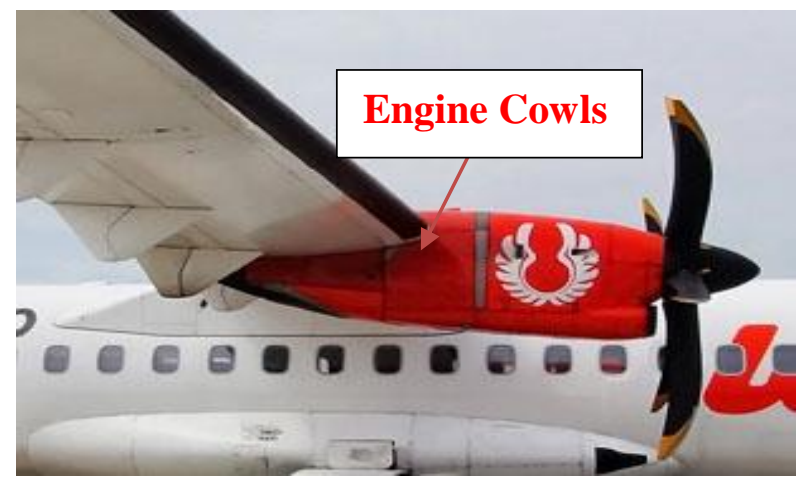

d. Menutup engine cowls.

Gambar 8. Kondisi Engine Cowls Tertutup

Setelah dilaksanakan pergantian outlet fuel filter dengan yang baru dilanjutkan dengan pengujian system, hasilnya engine tersebut dapat bekerja dengan baik (serviceable) tanpa adanya penyumbatan lagi, sehingga Pesawat ATR 72-500 PK-WFG dapat digunakan untuk beroperasi kembali.

\section{KESIMPULAN}

Berdasarkan data-data hasil yang didapat dari pemeriksaan faktor yang menyebabkan terjadinya warning light fuel clog pada pesawat ATR 72 - 500 PK-WFG, maka dapat diambil kesimpulan sebagai berikut:

(1) Faktor penyebab terjadinya warning light fuel clog pada pesawat ATR 72 - 500, karena adanya penyumbatan pada outlet fuel filter yang disebabkan menumpuknya kontaminasi sehingga mengakibatkan engine mengalami abnormal condition, dan juga kondisi tersebut dapat mengganggu system pengabutan yang ada di dalam combustion chamber sehingga pembakaran yang dihasilkan menjadi tidak sempurna. 
(2) Dari permasalahan ini, akibat yang terjadi pada sistem kerja fuel adalah sirkulasi kerja fuel yang tidak sempurna dan jika dibiarkan secara terus-menerus akan memberi pengaruh buruk terhadap komponenkomponen yang berkaitan dengan fuel system.

(3) Upaya penanggulangan adalah dengan melakukan pemeriksaan dan pengujian sistem pada Pesawat ATR 72-500 dan melakukan replacement outlet fuel filter (PN: 24436361-01) dengan yang baru, kemudian membersihkan cover outlet fuel filter dan melumaskan komponen-komponen yang berkaitan dengan outlet fuel filter sesuai dengan ketentuan Aircraft Maintenance Manual (AMM).

\section{Referensi}

(1) Aircraft Ttraining Manual Centre ATA Chapters 00 dan 70, Febuari 2002.

(2) Pratt \& Whitney Canada Training Manual Shop, Oktober 2017.

(3) Continous Aircraft Maintenance Program, Febuari 2002.

(4) Aircraft Maintenance Manual ATA Chapters 71, Desember 2017.

(5) Engine Maintenance Manual PW127 Fault Isolation ATA Chapter 72, April 2015.

(6) Planetpotters, "ATR PK-WFG Wings Air" https://www.Planespotters.net/photo/23624 2/pk-wfg-wings-air-atr-72-500-72-212a (diakses 9 November 2017).

(7) Atraircraft, "Spesifikasi Pesawat ATR 72500" https://www.atraircraft.com (diakses 17 Maret 2018). 